\title{
Validation of the 24-item recovery assessment scale-revised (RAS-R) in the Norwegian language and context: a multi- centre study
}

\author{
Eva Biringer ${ }^{1 *}$ (i) and Marit Tjoflåt ${ }^{2}$
}

\begin{abstract}
Background: The Recovery Assessment Scale-revised (RAS-R) is a self-report instrument measuring mental health recovery. The purpose of the present study was to translate and adapt the RAS-R into the Norwegian language and to investigate its psychometric properties in terms of factor structure, convergent and discriminant validity and reliability in the Norwegian context.

Methods: The present study is a cross-sectional multi-centre study. After a pilot test, the Norwegian version of the RAS-R was distributed to 231 service users in mental health specialist and community services. The factor structure of the instrument was investigated by a confirmatory factor analysis (CFA), and internal consistency was assessed by Cronbach's alpha.

Results: The RAS-R was found to be acceptable and feasible for service users. The original five-factor structure was confirmed. All model fit indices, including the standardised root mean square residual (SRMR), which is independent of the $x^{2}$-test, met the criteria for an acceptable model fit. Internal consistencies within sub-scales as measured by Cronbach's alpha ranged from 0.65 to 0.85 . Cronbach's alpha for the total scale was 0.90. As expected, some redundancy between factors existed (in particular among the factors Personal confidence and hope, Goal and success orientation and Not dominated by symptoms).

Conclusions: The Norwegian RAS-R showed acceptable psychometric properties in terms of convergent validity and reliability, and fit indices from the CFA confirmed the original factor structure. We recommend the Norwegian RAS-R as a tool in service users' and health professionals' collaborative work towards the service users' recovery goals and as an outcome measure in larger evaluations.
\end{abstract}

Keywords: Recovery, Mental health, Psychometric, Validation, Instrument, Assessment, Evaluation

\section{Background}

Earlier research has shown little correlation between personal recovery, as defined by service users, and the staff-rated tools frequently used as outcome measures in mental health [1,2]. Andresen and colleagues showed that recovery measures are measuring a unique construct that is not comprehensively assessed by conventional clinical measures [1]. Recovery in mental health

\footnotetext{
* Correspondence: eva.biringer@helse-fonna.no

1 Department of Research and Innovation, Helse Fonna Local Health

Authority, PO Box 2170, N-5504 Haugesund, Norway

Full list of author information is available at the end of the article
}

can be defined as 'a way of living a satisfying, hopeful and contributing life even with limitations caused by illness' [3]. It is conceptualised as both a process and an outcome, and improvement is not only reflected in changes in the state of the disorder (resolution) but can also be seen as an adjustment of life to work around the disorder (readjustment) or an adaptation to living with the disorder (redefinition) [4]. Hope and optimism about the future, purpose and meaningful activity, positive identity, connectedness and empowerment are central features of recovery [5-8]. However, no current 'goldstandard' measure of recovery exists $[9,10]$, and existing 
measures of recovery vary with regard to the constructs covered and their psychometric properties [9-13].

The Recovery Assessment Scale (RAS) is a self-report instrument measuring personal recovery that was developed more than 20 years ago by Giffort and colleagues in the US [14, 15]. At present, it is one of the most widely used measures of personal recovery [10-12, 16, 17]. Giffort and colleagues combined participatory action research and narrative analysis to generate a 41-item scale with adequate test-retest reliability and internal consistency [14, 15]. A study involving 1824 persons with serious mental health illness concluded that 24 of these items represented a meaningful five-factor solution [18]. The RAS-R thus consists of 24 items on five-level scales ('Strongly Disagree,' 'Disagree, 'Not Sure,' 'Agree, 'Strongly Agree') [18]. These items can be added up to produce summary scales representing five dimensions of personal recovery: Personal confidence and hope (items $7,8,9,10,11,12,13,14 \& 21$ ), Willingness to ask for help (items 18, 19 \& 20), Goal and success orientation (items 1, 2, 3, 4 \& 5), Reliance on others (items 6, 22, 23 \& 24), Not dominated by symptoms (items 15,16 \& 17) and a total scale. Sub- and total summary scales are frequently converted to mean scale scores [13].

Several systematic reviews have recommended the RAS as a tool for assessing personal recovery [11, 12], including as a routine tool in clinical settings [11]. A user-informed review performed by Law and colleagues (2012) concluded that the RAS is the most acceptable and valid measure currently available [9]. In their review of studies reporting psychometric properties of the RAS, Salzer and Brusilovskiy (2014) concluded that means and standard deviations across 28 studies were fairly consistent [13]. In longitudinal investigations included in their review, the instrument was found to be sensitive to change over time, and results for internal consistency of the scale, test-retest and inter-rater reliabilities were very good. Further, the factor structures found were consistent across studies. Based on these results, they recommended the instrument as a measure of recovery in clinical evaluations and research. There is still need for recovery research in the Nordic countries [19]. However, to conduct such research, instruments measuring personal recovery should be available in Nordic languages. The purpose of the present study was therefore to translate and adapt the RAS-R for use in a Norwegian context and to investigate its psychometric properties in terms of factor structure, convergent and discriminant validity and reliability.

\section{Methods}

Translation and adaptation of the RAS-R to the Norwegian language and context

Translation of the original RAS-R version into the Norwegian language was performed by an authorised translation bureau. Minor adaptations and adjustments of wordings were done after two service users and five health professionals commented on the first translated version. Lingual aspects, cultural adaption and cognitive issues were discussed by the project team, and the resulting version was then piloted with the help of nine service users at a day care unit in a community mental health centre. Five of the service users were women and four were men, their mean age was 30 years (range 1950) and they all had severe mental health conditions (psychosis spectrum disorders). They completed the instrument with the co-author MT as observer.

The participants in the pilot study experienced the questions as easily comprehensible. Several participants indicated that they felt the questions were particularly relevant for them, and completing the instrument obviously provoked reflections about the participants' personal recovery stories. However, some minor issues related to the comprehensibility and acceptability of some items were revealed among the participants. Like this participant, some found the interpretation of item 2, 'I have my own plan for how to stay or become well', to be challenging:

'Plan? No... I have small plans throughout the day, but it's like overall plan you mean? I'm trying to

understand what you mean ... I'll answer unsure as to whether I have a plan, at least I don't have a big plan.'

Most comments mentioned item 5, 'I have a purpose in life'. In this context 'purpose' could be translated into Norwegian as 'mål' ('goal'), 'formål' (purpose), 'hensikt' ('intention') and/or 'mening' ('meaning'). For instance, a young man who wished for a better social life and someone special to share his life with, found delimiting the item conceptually difficult:

'... I'm not sure, not about the question, but it's a bit "big" what they are asking about, almost as if they are asking about the meaning of life ...'

After discussing the feedback from the participants in the pilot study, the project team choose the term 'formål', which translates into 'goal', 'meaning' and 'purpose', as this term was perceived as the closest to the meaning of the item included in the original U.S. English version.

Item 11 ('I have an idea of who I want to become') was also confusing for some:

I have an idea of what I want ... Don't I want to become myself, then? [] But if it is education ..., [or] is it as a person ..? I think it's a bit of a vague question ...' 
Item 18 ('I know when to ask for help'), item 19 ('I am willing to ask for help') and item 20 ('I ask for help when I need it') were perceived as overlapping by some participants. Finally, two participants found the negative sentences in item 6 ('Even when I don't care about myself, other people do'), item 7 ('Fear doesn't stop me from living the way I want to') and item 15 ('Coping with my mental illness is no longer the main focus of my life') a bit confusing.

Based on feedback from the pilot study and discussions among the members of the project team, minor changes to wordings were made to the translated version in order to make the items clearer and more grammatically sound. A back-translated version was evaluated by the research team, and a few minor alterations in the introductory text were made, but no further changes were made to the items. The resulting Norwegian version of the RAS-R is included as Additional file 1 .

\section{Study design and setting}

To investigate the psychometric properties of the translated version of the RAS-R, we conducted a crosssectional multi-centre study in the mental health specialist and community services in the Haugaland and Sunnhordland regions on the west coast of Norway. The respondents were recruited from one municipality, four community mental health centres (CMHCs, i.e. secondary services) and one psychiatric hospital (i.e. tertiary service) according to predefined criteria (Table 1). The participating institutions varied in size and were situated in both urban and rural areas. As personal recovery is a longitudinal process $[4,20]$, we aimed at including participants representative of all stages of the recovery process. Therefore, a sub-sample of service users $(n=$ 85 ) who had been using mental health services 2 years ago, and who presumably had experienced partial or total recovery, were invited to participate. Data were collected from Spring 2015 until Autumn 2016.

\section{Participants}

The survey aimed to include ten respondents for each of the 24 items of the RAS-R. In all, 322 potential participants were regarded by their therapists as relevant to include according to the inclusion criteria. Of these, 231 (72\%) agreed to participate and provide informed consent. The participants received services at specialist level or had regular contact with community mental health services. The mental health services, inclusion criteria, participation rate and method of completing the RAS-R are shown in Table 1. The participants were asked to complete the 24-item RAS-R questionnaire along with information about their age, gender, level of education, civil status and employment status. In addition, the participants were asked to respond to the general question 'In your experience, where in your process of recovery are you now, compared to the situation when things were at the worst $(=1)$, and how you wish that your situation should ideally be $(=10)$ ?' Their responses were recorded on a visual analogue scale ranging from 1 to 10 . As there is no currently available gold standard among instruments measuring recovery as defined by service users, the RAS-R scores were correlated with this scale in order to provide support of the construct (convergent) validity of the RAS-R.

\section{Ethics}

All participants were regarded as able to provide consent, and all provided written informed consent. Approval for the study was sought from the Regional Committee for Medical Research Ethics (ref. no. 2009/ 1295). The Regional Committee for Medical Research Ethics referred the study to the Norwegian Social Science Data Services (NSD), which approved of the study (ref. no. 22920).

\section{Statistical analysis}

A confirmatory factor analysis (CFA) was conducted to assess the relationships between the observed (items) and latent (subscales) variables according to the predefined five-factor model of the RAS-R. The extent to which the factor structure of the Norwegian sample reflected the factor structure of the original instrument in English language was assessed by comparing the

Table 1 Overview of mental health care units, inclusion criteria, participation rate and way of completing the RAS-R

\begin{tabular}{|c|c|c|c|c|}
\hline Unit & Inclusion criteria & $n(\%)$ screened & $n(\%)$ included & $\begin{array}{l}\text { Way of completing } \\
\text { RAS-R }\end{array}$ \\
\hline $\begin{array}{l}\text { Mental health hospital with co-located CMHC } \\
\text { for adults }\end{array}$ & $\begin{array}{l}\text { Severe mental health condition and contact } \\
\text { with mental health services }>6-12 \text { months }\end{array}$ & $135(42)$ & $112(35)$ & Pencil and paper \\
\hline Two co-organised CMHCs for adults & & $66(21)$ & $52(16)$ & \\
\hline Mental health services in one municipality & Severe mental health condition & $36(11)$ & $32(10)$ & \\
\hline CMHC for adults & $\begin{array}{l}\text { Used mental health services } 2 \text { years ago due } \\
\text { to any mental health condition needing } \\
\text { specialist care }\end{array}$ & $85(26)$ & $35(11)$ & Telephone interview \\
\hline SUM & & $322(100)$ & $231(72)$ & \\
\hline
\end{tabular}


covariance matrix of the sample and the corresponding matrix estimated for the population [21, 22]. Due to the non-normal sample distributions, a maximum likelihood estimation with robust standard errors (MLM) was used to compute different indices of model fit, and the Satorra-Bentler (SB) scaled $\chi^{2}$-test was used to assess the goodness of fit. The normed $\chi^{2}$, which equals the $\chi^{2}$ divided by the degrees of freedom, was reported since it is less sensitive to sample size than the $X^{2}$. Estimates from a maximum likelihood estimation (ML) were reported in order to allow for comparisons with other studies. The fit criteria applied were in accordance with recommendations [23-26].

Spearman's rho correlation coefficient was computed between the visual analogue scale and the RAS-R totalscale. Average variance extracted (AVE) and composite reliability (CR) [27] were used to assess discriminant and convergent reliability. Convergent validity was regarded as acceptable if standardised factor loadings were $>0.50$, AVE was $>0.50$ and the internal consistency measure CR was larger than the AVE. Discriminant reliability was established if a factor explained more of the variance of its items than of the items belonging to other factors [28]. Further, discriminant validity was regarded as acceptable when the square root of the AVE for the factor was higher than its correlation with any other factor. As a rule of thumb, correlations between factors should be $<0.80$ [24]. Factor correlations exceeding 0.80 should be scrutinised carefully from a theoretical perspective with regard to discriminant validity.

At the sub-scale level, measures of CR higher than 0.70 were considered to be a basic requirement for reliability. Further, reliability was assessed by Cronbach's alpha, a measure of internal consistency between items within each sub-scale. Cronbach's alphas higher than 0.70 were considered acceptable.

The lavaan package (version 0.5-16 [29]) in the $R$ Software Package 3.0.2 (R Core team) was employed in the MLM-estimation. IBM SPSS AMOS 23 was used to assess the distribution assumptions, perform the MLestimation, and bivariate correlations and descriptive statistics were performed using IBM SPSS 23 (Armonk, NY; IBM Corp.). Tests were two-tailed with an alphalevel of 0.05 .

\section{Results}

\section{Respondents}

Three $(1 \%)$ of the respondents were excluded due to missing responses on three or more of the RAS-items, leaving $n=228$ with 21 or more items completed in the valid analysis file. Of these, 207 respondents completed all the RAS-R items. Missing items were replaced by the median of nearby points (span of nearby points was 2 ) for 21 respondents. The respondents represented a wide range of service types and mental health conditions. The sociodemographic and clinical characteristics of the respondents included in the valid analysis file $(n=228)$ are displayed in Table 2.

As for the RAS-R responses, the score distributions were explored in terms of univariate and multivariate normality. As outliers may influence parameter estimation, the Mahalanobis distance from the centroid was examined to detect potential outliers in AMOS [22]. The preanalytic screening displayed considerable multivariate kurtosis and some outliers. Mardia's coefficient was 157.245, and 12 observations were identified as outliers according to the Mahalanobis distance [24]. However, the outliers were perceived as true variations of the scores in the sample, as they were regarded as representative of the respondents' experiences of their personal recoveries. Descriptive statistics of the RAS-R item responses, mean sub- and total scale scores are presented in Table 3.

\section{Confirmatory factor analysis}

As shown in Table 4, all model fit indices, including the SRMR, which is independent of the $x^{2}[24,30,31]$, met the criteria for acceptable model fit. However, the SB $X^{2}$ remained statistically significant $(p=0.000)$. The suggested model was over-identified with 300 distinct sample moments, 58 parameters and 242 degrees of freedom. Figure 1 shows the resultant five-factor model with the standardised regression weights for each item and factor correlations. Table 5 shows the parameter estimates with standard errors (SE) from the CFA.

\section{Convergent and discriminant validity}

Table 6 provides vital information for assessing convergent and discriminant validity issues and shows correlations between items, between items and factors and inter-factor correlations. Convergent validity was supported, as all the items loaded mostly on their respective parent factors. Further, the findings that most standardised factor loadings (range 0.33-0.90) (Table 5) and correlations between items within each factor (range $0.47-0.90$ ) (Table 6) were moderate to high supported convergent validity, implying that the latent factors were explained by their items. However, four of the twentynine factor loadings (RAS1 (standardised factor loading 0.35), RAS7 (0.38), RAS11 (0.46), and RAS24 (0.33)) were below the basic requirement of 0.5 for establishing convergent validity at the item level (Table 5). The items RAS1, RAS7 and RAS24 had the lowest correlations with their parent factors $(0.34,0.38$ and 0.33 , respectively). Comparing the $\mathrm{CR}$ values to the AVE values across factors revealed that all CRs were higher than their respective AVEs, indicating good convergent validity. Convergent validity for the factors Willingness to ask for help and Not dominated by symptoms were further 
Table 2 Descriptives of the valid sample $(n=228)$

\begin{tabular}{|c|c|c|c|}
\hline Variable & & Mean (SD) & Range \\
\hline Age (years) & & $41(14.2)$ & $18-77$ \\
\hline \multirow[t]{2}{*}{ Visual Analogue Scale } & $\begin{array}{l}\text { In your experience, where in your process of recovery are } \\
\text { you now, compared to where you were when things were } \\
\text { at the worst }(=1) \text {, and how you wish that your situation } \\
\text { should ideally be }(=10)\end{array}$ & $6.1(2.04)$ & $1-10$ \\
\hline & & Number & Percent \\
\hline \multirow[t]{2}{*}{ Gender } & Man & 99 & 43 \\
\hline & Woman & 128 & 56 \\
\hline \multirow[t]{3}{*}{ Highest completed level of education } & Nine years compulsory school & 63 & 28 \\
\hline & High school & 125 & 55 \\
\hline & University/college & 36 & 16 \\
\hline \multirow[t]{6}{*}{ Civil status } & Married & 45 & 20 \\
\hline & Co-habiting & 29 & 13 \\
\hline & Single & 116 & 51 \\
\hline & Divorced/separated & 23 & 10 \\
\hline & Widow (-er) & 3 & 1.3 \\
\hline & Other & 5 & 2.2 \\
\hline \multirow[t]{10}{*}{ Work status ${ }^{\mathrm{a}}$} & Employed & 43 & 19 \\
\hline & Self-employed & 4 & 1.8 \\
\hline & Supported employment & 3 & 1.3 \\
\hline & Domestic work & 2 & 0.9 \\
\hline & Disability pension & 98 & 43 \\
\hline & Student & 11 & 5 \\
\hline & Out of work & 7 & 3 \\
\hline & Retired & 4 & 1.8 \\
\hline & Sick leave & 44 & 19 \\
\hline & Other & 6 & 2.6 \\
\hline \multirow[t]{3}{*}{ Mental health service use } & Out-patient, specialist services & 167 & 63 \\
\hline & In-patient, specialist services & 24 & 11 \\
\hline & Community mental health services & 31 & 14 \\
\hline \multirow[t]{11}{*}{ ICD-10 primary diagnosis } & F00-F09 Organic, including symptomatic, mental disorders & 1 & 0.4 \\
\hline & $\begin{array}{l}\text { F10-F19 Mental and behavioural disorders due to psychoactive } \\
\text { substance use }\end{array}$ & 12 & 5 \\
\hline & F20-F29 Schizophrenia, schizotypal and delusional disorders & 37 & 16 \\
\hline & F30-F39 Mood disorders & 56 & 25 \\
\hline & F40-F48 Neurotic, stress-related and somatoform disorders & 67 & 29 \\
\hline & $\begin{array}{l}\text { F50-F59 Behavioural syndromes associated with physiological } \\
\text { disturbances and physical factors }\end{array}$ & 8 & 4 \\
\hline & F60-F69 Disorders of adult personality and behaviour & 18 & 8 \\
\hline & F70-F79 Mental retardation & 0 & 0 \\
\hline & F80-F89 Disorders of psychological development & 2 & 0.9 \\
\hline & $\begin{array}{l}\text { F90-F98 Behavioural and emotional disorders with onset } \\
\text { usually occurring in childhood and adolescence }\end{array}$ & 11 & 5 \\
\hline & Other & 11 & 5 \\
\hline
\end{tabular}

$M$ means, SD standard deviation, ICD-10 World Health Organization International Classification of Diseases version 10 
Table 3 Descriptives of the RAS-R items and summary scales in the valid sample $(n=228)$

\begin{tabular}{|c|c|c|c|c|}
\hline Item & Mean & SD & Range & $95 \% \mathrm{Cl}$ \\
\hline 1. I have a desire to succeed & 4.6 & 0.62 & $1-5$ & $4.56 ; 4.72$ \\
\hline 2. I have my own plan for how to stay or become well & 3.9 & 0.92 & $1-5$ & $3.80 ; 4.05$ \\
\hline 3. I have goals in life that I want to reach & 4.2 & 0.90 & $1-5$ & $4.08 ; 4.32$ \\
\hline 4. I believe that I can meet my current personal goals & 3.7 & 0.98 & $1-5$ & $3.59 ; 3.85$ \\
\hline 5. I have a purpose in life & 3.8 & 0.94 & $1-5$ & $3.72 ; 3.97$ \\
\hline 6. Even when I don't care about myself, other people do & 4.1 & 0.83 & $1-5$ & $4.0 ; 4.21$ \\
\hline 7. Fear doesn't stop me from living the way I want to & 3.1 & 1.30 & $1-5$ & $2.90 ; 3.25$ \\
\hline 8. I can handle what happens in my life & 3.3 & 1.02 & $1-5$ & $3.20 ; 3.47$ \\
\hline 9. I like myself & 3.2 & 1.20 & $1-5$ & $2.99 ; 3.31$ \\
\hline 10. If people really knew me, they would like me & 3.7 & 0.84 & $1-5$ & $3.60 ; 3.82$ \\
\hline 11. I have an idea of who I want to become & 3.5 & 1.05 & $1-5$ & $3.40 ; 3.67$ \\
\hline 12. Something good will eventually happen & 4.0 & 0.81 & $1-5$ & $3.93 ; 4.14$ \\
\hline 13. I'm hopeful about my future & 3.9 & 0.99 & $1-5$ & $3.72 ; 3.97$ \\
\hline 14. I continue to have new interests & 3.7 & 1.09 & $1-5$ & $3.57 ; 3.86$ \\
\hline 15. Coping with my mental illness is no longer the main focus of my life & 3.1 & 1.23 & $1-5$ & $2.98 ; 3.30$ \\
\hline 16. My symptoms interfere less and less with my life & 3.4 & 1.20 & $1-5$ & 3,$25 ; 3.54$ \\
\hline 17. My symptoms seem to be a problem for shorter periods of time each time they occur & 3.5 & 1.13 & $1-5$ & $3.32 ; 3.61$ \\
\hline 18. I know when to ask for help & 3.9 & 1.06 & $1-5$ & $3.78 ; 4.05$ \\
\hline 19. I am willing to ask for help & 4.1 & 0.92 & $1-5$ & $4.01 ; 4.25$ \\
\hline 20. I ask for help when I need it & 3.8 & 1.08 & $1-5$ & $3.68 ; 3.96$ \\
\hline 21. I can handle stress & 3.0 & 1.14 & $1-5$ & $2.88 ; 3.18$ \\
\hline 22. I have people I can count on & 4.3 & 0.78 & $1-5$ & $4.18 ; 4.38$ \\
\hline 23. Even when I don't believe in myself, other people do & 4.0 & 0.87 & $1-5$ & $3.88 ; 4.10$ \\
\hline 24. It is important to have a variety of friends & 3.5 & 1.40 & $1-5$ & $3.31 ; 3.67$ \\
\hline \multicolumn{5}{|l|}{ Summary scales } \\
\hline Personal confidence and hope (mean of items $7,8,9,10,11,12,13,14$ \& 21) & 3.5 & 0.68 & $1.67-5$ & $3.40 ; 3.58$ \\
\hline Willingness to ask for help (mean of items $18,19 \& 20$ ) & 4.0 & 0.89 & $1-5$ & $3.84 ; 4.07$ \\
\hline Goal and success orientation (mean of items $1,2,3,4$ \& 5) & 4.1 & 0.63 & $1.4-5$ & $3.99 ; 4.15$ \\
\hline Reliance on others (mean of items 6, 22, 23 \& 24) & 4.0 & 0.68 & $2-5$ & $3.88 ; 4.06$ \\
\hline Not dominated by symptoms (mean of items $15,16 \& 17$ ) & 3.3 & 0.95 & $1-5$ & $3.21 ; 3.45$ \\
\hline Total scale (mean of items) & 3.7 & 0.56 & $1.92-5$ & $3.66 ; 3.80$ \\
\hline Total scale (sum of items) & 89.5 & 13.39 & $46-120$ & $87.75 ; 91.24$ \\
\hline
\end{tabular}

$M$ means, $S D$ standard deviation, $C l$ confidence interval

Table 4 Fit criteria and global fit assessed by robust Satorra-Bentler (MLM) and ML estimators $(n=228)$

\begin{tabular}{llll}
\hline Model & Fit-criterion & MLM-robust & $\mathrm{ML}$ \\
\hline $\mathrm{X}^{2}$ & $>.05$ & 360.699 & 493.608 \\
$p$ & & .000 & .000 \\
$d f$ & 242 & 242 \\
Normed $\mathrm{X}^{2}$ & $<5.0$ & 1.49 & 2.04 \\
CFI & $\geq .90$ & 0.924 & 0.876 \\
TLI & $\geq .90$ & 0.913 & 0.858 \\
RMSEA & $\leq .06$ & 0.046 & 0.068 \\
RMSEA 90\% Cl & $.06-.08$ & $.038-.055$ & $.059-0.076$ \\
SRMR & $\leq .08$ & 0.063 & 0.063 \\
\hline
\end{tabular}

$M L$ maximum likelihood, $M L M$ maximum likelihood mean-adjusted, $d f$ degrees of freedom, CFI Bentler comparative fit index, TLI Tucker-Lewis incremental index, RMSEA Steiger-Lind root mean square error of approximation, $\mathrm{Cl}$ confidence interval, SRMR standardised root mean square residual supported by AVE values >0.50. However, AVE estimates for the other three factors were below the threshold of 0.50 for convergent validity at the sub-scale level (Table 7).

The bivariate correlation (Spearman's rho) was 0.59 $(p<0.000)$ between the participants' responses to the question 'In your experience, where in your process of recovery are you now, compared to where you were when things were at the worst $(=1)$, and how you wish that your situation should ideally be $(=10)^{\prime}$ and the RAS-R total scale.

Discriminant validity was supported by the finding that each parent factor explained more of the variance of its items than of the items belonging to the other factors. Comparing the square roots of the AVEs of the 


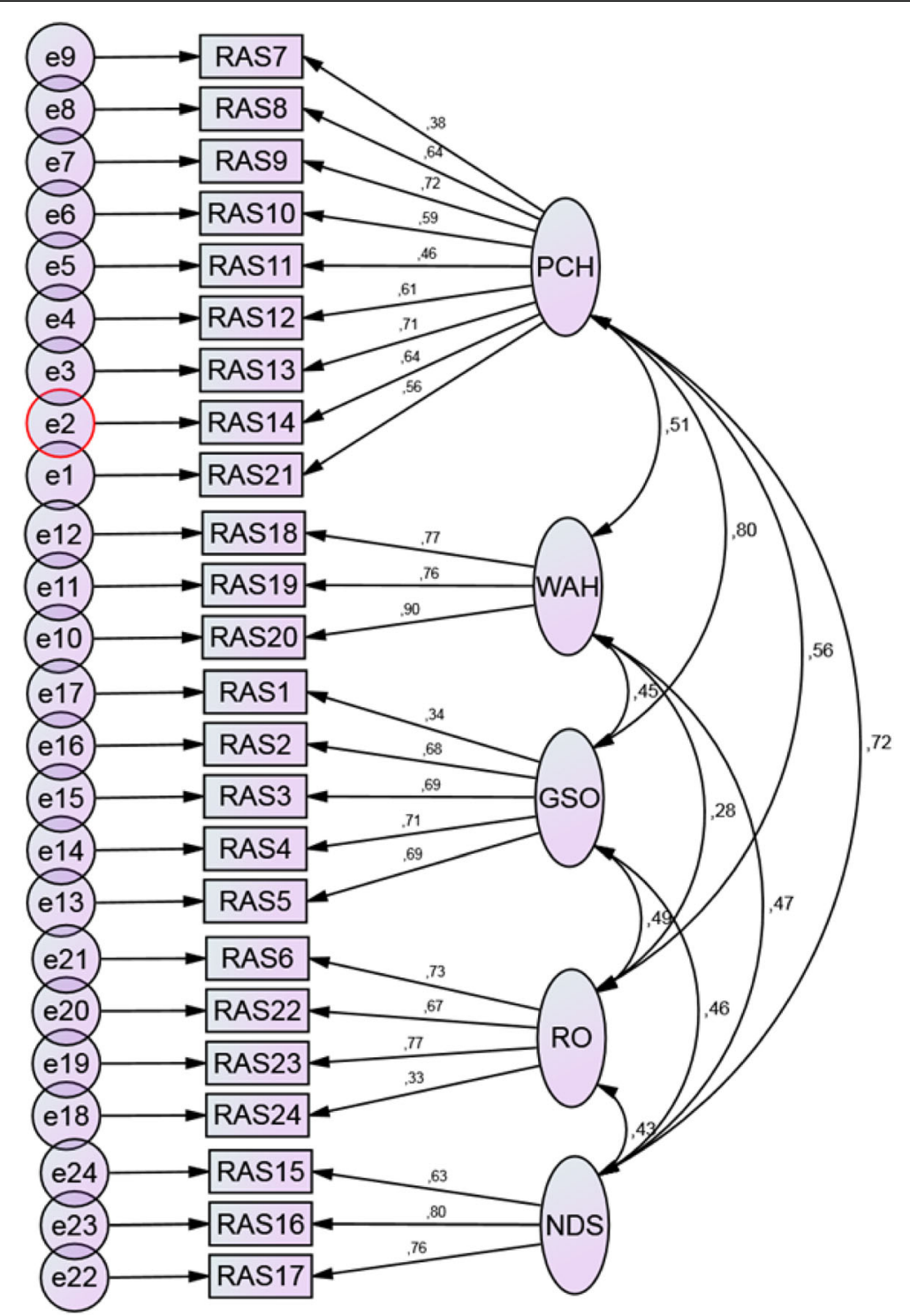

Fig. 1 RAS-R five-factor model supplied with the standardised regression weights for each item and factor correlations. Observed variables are displayed as rectangles connected to latent factors visualised as ellipses that represent the constructs. The direction of the straight arrows indicate that observed variables should be explained by their corresponding latent factors. The two-headed curved arrows between the constructs show that they are correlated. The small circles represent measurement errors unique to each observed variable that do not contribute to explaining any variance on factor level PCH Personal confidence and hope (RAS 7, 8, 9, 10, 11, 12, 13, 14, 21), WAH Willingness to ask for help (RAS18, 19, 20), GSO Goal and success orientation (RAS 1, 2, 3, 4, 5), RO Reliance on others (RAS 6, 22, $23,24)$ and NDS Not dominated by symptoms (RAS 15, 16, 17)

factors (the diagonals in Table 7) to their respective factor's correlation with any other factor (Table 6) revealed that the discriminant abilities of three factors were acceptable. However, the discriminant abilities of the factors Goal and success orientation and Personal confidence and hope could be questioned. The factor Goal and success orientation factor showed a factor correlation at the limit of 0.80 for discriminant validity (Table 6). The inter-construct correlations of the Goal and success orientation factor with the Personal confidence and cope-factor, and the Personal confidence and hope factor with the Not dominated by symptoms factor, were higher than the square roots of their respective AVEs (Table 7). Some correlation, or redundancy, was present between factors (i.e. correlation coefficients $\geq 0.70$; Table 6 ).

\section{Reliability}

Indicator reliability, as measured by the explained variance in Table 5, ranged from a lower communality, 0.11 for 
Table 5 Standardised ( $\beta$ ) factor loadings, communalities, and unstandardised (B) factor loadings with standard errors (SE)

\begin{tabular}{|c|c|c|c|c|}
\hline \multicolumn{5}{|c|}{ Personal confidence and hope-factor } \\
\hline Item & $\beta$ & Communality & B & SE \\
\hline RAS7 & 0.38 & 0.15 & 0.79 & 0.16 \\
\hline RAS8 & 0.64 & 0.41 & 1.04 & 0.14 \\
\hline RAS9 & 0.72 & 0.51 & 1.38 & 0.17 \\
\hline RAS10 & 0.59 & 0.35 & 0.78 & 0.11 \\
\hline RAS11 & 0.46 & 0.21 & 0.77 & 0.13 \\
\hline RAS12 & 0.61 & 0.37 & 0.78 & 0.11 \\
\hline RAS13 & 0.71 & 0.50 & 1.11 & 0.14 \\
\hline RAS14 & 0.64 & 0.41 & 1.11 & 0.15 \\
\hline RAS21 & 0.56 & 0.31 & 1.00 & \\
\hline \multicolumn{5}{|c|}{ Willingness to ask for help-factor } \\
\hline Item & $\beta$ & Communality & B & SE \\
\hline RAS18 & 0.77 & 0.59 & 0.83 & 0.07 \\
\hline RAS19 & 0.76 & 0.68 & 0.72 & 0.06 \\
\hline RAS20 & 0.90 & 0.81 & 1.00 & \\
\hline \multicolumn{5}{|c|}{ Goal and success orientation-factor } \\
\hline Item & $\beta$ & Communality & B & SE \\
\hline RAS1 & 0.35 & 0.13 & 0.33 & 0.07 \\
\hline RAS2 & 0.68 & 0.46 & 0.97 & 0.11 \\
\hline RAS3 & 0.69 & 0.48 & 0.96 & 0.11 \\
\hline RAS4 & 0.71 & 0.50 & 1.07 & 0.12 \\
\hline RAS5 & 0.69 & 0.48 & 1.00 & \\
\hline \multicolumn{5}{|c|}{ Reliance on others-factor } \\
\hline Item & $\beta$ & Communality & B & SE \\
\hline RAS6 & 0.73 & 0.53 & 1.35 & 0.30 \\
\hline RAS22 & 0.68 & 0.46 & 1.16 & 0.27 \\
\hline RAS23 & 0.77 & 0.59 & 1.48 & 0.33 \\
\hline RAS24 & 0.33 & 0.11 & 1.00 & \\
\hline \multicolumn{5}{|c|}{ Not dominated by symptoms-factor } \\
\hline Item & $\beta$ & Communality & B & SE \\
\hline RAS15 & 0.63 & 0.40 & 0.90 & 0.11 \\
\hline RAS16 & 0.80 & 0.64 & 1.06 & 0.10 \\
\hline RAS17 & 0.76 & 0.58 & 1.00 & \\
\hline
\end{tabular}

RAS24, to the higher end, 0.81 for RAS20. At the sub-scale level, all CRs were well above 0.70 (Table 7). Further, internal consistencies within sub-scales as measured by Cronbach's alpha were 0.83 for the Personal confidence and hope, 0.85 for the Willingness to ask for help, 0.77 for the Goal and success orientation, 0.65 for the Reliance on others and 0.76 for the Not dominated by symptoms factors, respectively. Cronbach's alpha for the total scale was 0.90 .

\section{Discussion}

The present study supports the Norwegian version of the RAS-R for use in the Norwegian language and context. The translation of the instrument into the Norwegian language was thorough and included feedback from service users with long experience of severe mental health issues. The pilot study indicated that the instrument was acceptable and feasible for service users. A few comments made by the respondents during the piloting suggested challenges with the comprehensibility of item 5 ('I have a purpose in life') and items that were negatively worded. These challenges were, however, minor and did not lead to any re-phrasings that would make the Norwegian version of the RAS-R deviate from the original U.S. English version.

Earlier studies have concluded that the core values and concepts of recovery have transcultural relevance [32-34]. Mean RAS-R scores in the present study were comparable to mean scores in earlier studies using the RAS or RAS-R, most of which were performed in the English-speaking part of the world [13]. However, a transcultural study performed in Japan and the US found differences in RAS-R response patterns between the two countries [34]. The lower means on the Goal and success orientation and Reliance on others sub-scales reported by Japanese respondents, as compared to US respondents, was explained by differences in emphasis of aspects of hope, personal confidence and collectivism between Eastern and Western cultures. In the present study mean RAS-R scores appeared similar to the scores reported by Cavelti et al. (2017) in their recent study from the German cultural context [35]. The fact that mean RAS-R responses in the Norwegian context were similar to the responses in the study set in the German context, may reflect similarity in cultures among these two countries. For instance, the way psychological constructs such as personal recovery are viewed, and the interpretation and use of language, may be similar. Probably, the similarity in mean RAS-R scores found in the present study compared to earlier studies in the Western world $[13,35]$ also indicates high validity of the newly translated Norwegian version of the RAS-R. Therefore results from studies using the Norwegian RAS-R may be transferred to countries belonging to the same cultural sphere.

In the present study the results from the CFA, i.e. the goodness-of-fit estimates and parameter estimates, yielded acceptable results, supporting the established five-factor structure from the original U.S. RAS-R version [18]. The construct (convergent) validity of the RAS-R was supported by the correlation between the RAS-R and the visual analogue scale representing responses to the question 'In your experience, where in your process of recovery are you now, compared to 


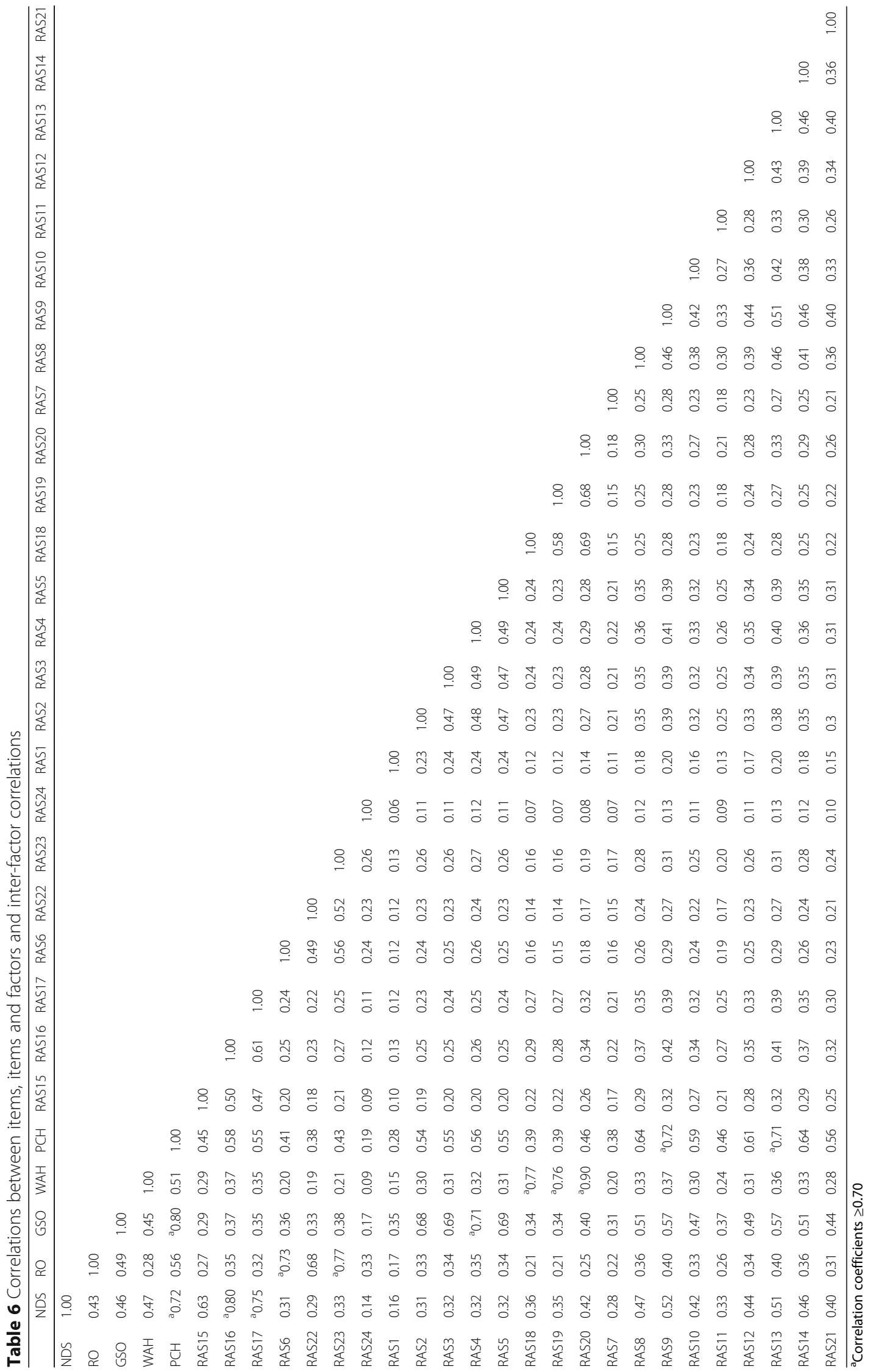


Table 7 Convergent and discriminant validity test with factor correlations

\begin{tabular}{|c|c|c|c|c|c|c|c|}
\hline & $C R$ & $\mathrm{AVE}^{\mathrm{a}}$ & $\begin{array}{l}\text { Personal Confidence } \\
\text { and Hope }\end{array}$ & $\begin{array}{l}\text { Willingness to } \\
\text { Ask for Help }\end{array}$ & $\begin{array}{l}\text { Goal and Success } \\
\text { Orientation }\end{array}$ & $\begin{array}{l}\text { Reliance on } \\
\text { Others }\end{array}$ & $\begin{array}{l}\text { Not Dominated } \\
\text { by Symptoms }\end{array}$ \\
\hline Personal confidence and hope & 0.830 & 0.359 & 0.599 & 0.429 & & & \\
\hline Willingness to ask for help & 0.851 & 0.657 & 0.429 & 0.811 & & & \\
\hline Goal and success orientation & 0.764 & 0.401 & 0.611 & 0.434 & 0.633 & & \\
\hline Reliance on others & 0.732 & 0.423 & 0.462 & 0.286 & 0.407 & 0.650 & \\
\hline Not dominated by symptoms & 0.774 & 0.536 & 0.620 & 0.423 & 0.354 & 0.362 & 0.732 \\
\hline
\end{tabular}

CR composite reliability, AVE average variance extracted (squared factor loadings averaged)

Diagonals show square roots of AVE; values in italics may indicate discriminant validity issues (i.e. factors other than the parent factor may explain more of the item variance)

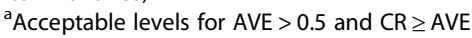

where you were when things were at the worst $(=1)$, and how you wish that your situation should ideally be $(=10)^{\prime}$. This visual analogue scale was used to operationalise the construct of 'personal recovery' in the present study, as no 'gold-standard' measure of this construct exists. The validity of the visual analogue scale was probably lower than any 'gold-standard' measure of personal recovery would have been. However, although the correlation between the RAS-R and the visual analogue scale probably was weakened due to lower validity of the visual analogue scale, we argue that the correlation found between RAS-R and the visual analogue scale in the present study supports the convergent validity of the Norwegian RAS-R. Convergent validity was further supported since all the items loaded mostly on their respective parent factors, most standardised factor loadings and correlations between items within each factor were moderate to high and the CRs were above the AVEs of the respective factors. This means that the latent factors (sub-scales) were supported by their items. However, convergent validity was not completely supported for the Personal confidence and hope, Goal and success orientation and Reliance on others factors, as their AVE values were below the levels usually regarded as acceptable. Reliability and internal consistency of the RAS-R sub-scales were found to be good. The discriminant ability of the Personal confidence and hope factor may, however, be questionable, as the square root of the AVE of this factor was slightly larger than the factor's correlation with the Goal and success orientation and Not dominated by symptoms factors, suggesting some overlap between these sub-scales. However, some degree of overlap between sub-scales may be expected within instruments measuring psychosocial constructs. In the present study, the inclusion of service users with a wide range of types of mental health problems probably reduced the risk of sampling biases and increased the reliability and generalisability of the findings. As personal recovery is a longitudinal process that occurs in stages $[4,20]$, participants who had experienced partly or total recovery was included in order to increase variance in the construct explored. However, some limitations need to be discussed. One concern is the fact that the back-translation of the Norwegian RAS-R into English language was evaluated by the research team and not by independent experts. However, inconsistencies between the back-translated version and the original version in U.S. English were very minor and thus it is unlikely that this limitation lead to inconsistency between the original and the translated version. Although visual inspection revealed no systematic pattern in missing item responses, we cannot exclude the possibility that replacing missing items lead to biases in responses. Another concern is the rejection of the predefined measurement model by the SB $X^{2}$ test. Sample size, communalities and model complexity influence the SB $\chi^{2}$ test, which is not considered reliable for $N>200$ samples [24, $31,36]$. However, in the present study, the normed $x^{2}$ was within acceptable ranges [23]. Consequently, the conclusion about how well the proposed model fitted was based on both the theory and the evaluation of the indices of model fit, the normed $X^{2}$ and relevant estimates of validity and reliability, rather than the SB $\chi^{2}$ test. Finally, the data were cross-sectional and did not allow for assessment of instrument properties such as test-retest reliability and responsiveness to change.

\section{Conclusions}

We conclude that the RAS-R is an acceptable, feasible, valid and reliable tool for assessing mental health recovery, as defined and experienced by service users, in the Norwegian language and context. Hopefully, the Norwegian RAS$\mathrm{R}$ will become a useful tool for service users and health professionals in their collaborative work towards the service users' recovery goals. Patient-based outcome measures such as the RAS-R should be used in future evaluations and research in order to increase the validity of findings by capturing central features of mental health recovery that are not captured by traditional clinical instruments. Future studies assessing the psychometric properties of the RAS-R should have longitudinal designs in order to allow for the evaluation of test-retest reliability and responsiveness. 


\section{Abbreviations}

AVE: Average variance extracted; CFA: Confirmatory factor analysis; CFI: Bentler comparative fit index; Cl: Confidence interval; CMHC: Community Mental Health Centre; CR: Composite reliability; Df: Degrees of freedom; GSO: Goal and success orientation sub-scale; ML: Maximum likelihood estimation; MLM: Maximum likelihood estimation with robust standard errors; NDS: Not dominated by symptoms sub-scale; PCH: Personal confidence and hope sub-scale; RAS-R: Recovery Assessment Scale-revised; RMSEA: Steiger-Lind root means square error of approximation; RO: Reliance on others sub-scale; SB: Satorra-Bentler; SD: Standard deviation; SE: Standard error; SRMR: Standardised root mean square residual; TLI: Tucker-Lewis incremental index; WAH: Willingness to ask for help sub-scale

\section{Acknowledgements}

We thank Patrick Corrigan, Distinguished Professor of Psychology at the Illinois Institute of Technology, IL, US, for granting us the permission to use and translate the RAS-R and for his useful advice during the translation process. We thank all the service users who participated in the study. We also thank Magnhild Kamrud Kalstø and other key personnel involved in the collection of data in Helse Fonna Local Health Trust and Kvinnherad Municipality, Norway. Finally, we want to express gratitude to Jörg Aßmus, who is a statistician at the Centre for Clinical Research, Haukeland University Hospital, Bergen, Norway, for his help with the confirmatory factor analysis, and to Marit Borg at the University College of Southeast Norway for her advice during the piloting of the RAS-R.

\section{Funding}

The project was partly funded by a personal grant to EB from the Norwegian Extra Foundation for Health and Rehabilitation/Norwegian Council for Mental Health (grant no. 2010/2/0299). The other author received wages from the Helse Fonna Local Health Trust, Norway.

\section{Availability of data and materials}

The datasets used in the current study are not publicly available as they are storaged under license from the Norwegian Social Science Data Services (NSD). However, summary statistics and details of the data are available from the authors upon reasonable request.

\section{Authors' contributions}

MT and EB conceived and planned the study. MT was responsible for the data collection. EB wrote the first manuscript draft, which was thoroughly revised by MT. Both authors read and approved the final manuscript.

\section{Authors' information}

MT, MSc, is a clinical social worker with many years of experience in working with service users with severe mental health issues. $\mathrm{EB}, \mathrm{MD}, \mathrm{PhD}$, is a researcher with clinical experience in mental health specialist services and general practice.

\section{Ethics approval and consent to participate}

All participants provided written informed consent. Approval for the study was applied for from the Regional Committee for Medical Research Ethics (ref. no. 2009/1295). The Regional Committee for Medical Research Ethics referred the study to the Norwegian Social Science Data Services (NSD), which was regarded as the most appropriate body to approve of this kind of research. The NSD approved the study (ref. no. 22920).

\section{Consent for publication}

Not applicable.

\section{Competing interests}

The authors declare that they have no competing interests.

\section{Publisher's Note}

Springer Nature remains neutral with regard to jurisdictional claims in published maps and institutional affiliations.

\section{Author details}

'Department of Research and Innovation, Helse Fonna Local Health Authority, PO Box 2170, N-5504 Haugesund, Norway. ${ }^{2}$ Folgefonn Community
Mental Health Centre, Division of Psychiatry, Helse Fonna Local Health Authority, Sjukehusvn. 14, N-5451 Valen, Norway.

Received: 22 September 2017 Accepted: 17 January 2018

Published online: 25 January 2018

\section{References}

1. Andresen R, Caputi P, Oades L. Do clinical outcome measures assess consumer-defined recovery? Psychiatry Res. 2010;177:309-17.

2. Connell J, Brazier J, O'Cathain A, Lloyd-Jones M, Paisley S. Quality of life of people with mental health problems: a synthesis of qualitative research. Health Qual Life Outcomes. 2012;10:138.

3. Anthony WA. Recovery from mental illness: the guiding vision of the mental health service system in the 1990s. Psychosoc Rehab J. 1993;16:11-23.

4. Davidson $L$, Roe $D$. Recovery from versus recovery in serious mental illness: one strategy for lessening confusion plaguing recovery. J Ment Health. 2007;16:459-70.

5. Anthony WA. A recovery-oriented service system: setting some system level standards. Psychiatr Rehabil J. 2000;24:159-68.

6. Davidson L, O'Connell M, Tondora J, Lawless M, Evans A. Recovery in serious mental illness: a new wine or just a new bottle? Prof Psychol: Res Practice. 2005:36:480-7.

7. Slade M, Leamy M, Bacon F, Janosik M, Le Boutillier C, Williams JJ, Bird V. International differences in understanding recovery: systematic review. Epidemiol Psychiatr Serv. 2012;21:353-64.

8. Chambers E, Cook S, Thake A, Foster A, Shaw S, Hutten R, Parry G, Ricketts T. The self-management of longer-term depression: learning from the patient, a qualitative study. BMC Psychiatry. 2015;15:172.

9. Law H, Morrison A, Byrne R, Hodson E. Recovery from psychosis: a user informed review of self-report instruments for measuring recovery. J Ment Health. 2012;21:192-207.

10. Shanks V, Williams J, Leamy M, Bird VJ, Le Boutillier C, Slade M. Measures of personal recovery: a systematic review. Psychiatr Serv. 2013;64:974-80.

11. Burgess P, Pirkis J, Coombs T, Rosen A. Assessing the value of existing recovery measures for routine use in Australian mental health services. Aust N Z J Psychiatry. 2011;45:267-80.

12. Cavelti M, Kvrgic S, Beck EM, Kossowsky J, Vauth R. Assessing recovery from schizophrenia as an individual process. A review of self-report instruments. Eur Psychiatry. 2012;27:19-32.

13. Salzer MS, Brusilovskiy E. Advancing recovery science: reliability and validity properties of the recovery assessment scale. Psychiatr Serv. 2014;65:442-53.

14. Giffort D, Schmook A, Woody C, Vollendorf C, Germain M. Construction of a scale to measure consumer recovery. Springfield: Illinois Office of Mental Health; 1995.

15. Corrigan PW, Giffort D, Rashid F, Leary M, Okeke I. Recovery as a psychological construct. Community Ment Health J. 1999;35:231-9.

16. Campbell-Orde T, Chamberlin J, Carpenter J, Leff H. Measuring the promise: a compendium of recovery measures, vol. II. Cambridge: Human Services Research Institute; 2005.

17. Khanam D, McDonald K, Neils C. In: NYC Department of Mental Health and Hygiene, editor. Measuring recovery: a toolkit for mental health providers in new York City, vol. 1. N.Y.C: Bureau of Mental Health; 2013.

18. Corrigan PW, Salzer M, Ralph RO, Sangster $Y$, Keck L. Examining the factor structure of the recovery assessment scale. Schizophr Bull. 2004:30:1035.

19. Schön UK, Rosenberg D. Transplanting recovery: research and practice in the Nordic countries. J Ment Health. 2013:22:563-9.

20. Andresen $R$, Oades $L$, Caputi $P$. The experience of recovery from schizophrenia: towards an empirically validated stage model. Aust N Z J Psychiatry. 2003;37:586-94.

21. Brown TA. Confirmatory factor analysis for applied research, vol. 455. New York: The Guilford Press; 2006.

22. Ullman JB. Structural equation modeling: reviewing the basics and moving forward. J Person Assess. 2006:87:35-50.

23. Schumacker R, Lomax R. A beginner's guide to structural equation modeling. 2nd ed. Mahwah: Lawrence Erlbaum Associates; 2004.

24. Kline RB. Principles and practices of structural equation modeling. 2nd ed. New York: Guilford Press; 2005

25. Newsom J. Practical approaches to dealing with nonnormal and categorical variables. http://web.pdx.edu/ newsomj/semclass/ho estimate2.pdf. Accessed 23 Jan 2018. 
26. Schreiber JB, Nora A, Stage FK, Barlow EA, King J. Reporting structural equation modeling and confirmatory factor analysis results: a review. J Educ Res. 2006;99:323-38.

27. Hair JB, Babin B, Anderson R. Multivarate data analysis. 7th ed. Upper Saddle River: Prentice-Hall, Inc.; 2010

28. Farrell AM. Insufficient discriminant validity: a comment on Bove, Pervan, Beatty, and Shiu (2009). J Bus Res. 2010;63:324-7.

29. Rosseel Y. Lavaan: an R package for structural equation modeling. I Stat Softw. 2012:48:1-46.

30. Hu LT, Bentler PM. Cutoff criteria for fit indexes in covariance structure analysis: conventional criteria versus new alternatives. Structural Equation Modeling: A Multidisc J. 1999;6:1-55.

31. Jackson DL, Gillaspy JA, Purc-Stephenson R. Reporting practices in confirmatory factor analysis: an overview and some recommendations. Psychol Methods. 2009:14:6-23.

32. Davidson L, Borg M, Martin I, Topor A, Mezzina R, Sells D. Processes of recovery in serious mental illness: findings from a multi-national study. Am J Psychiatr Rehabil. 2005;8:177-201.

33. Chiu MY, Ho WW, Lo WT, Yiu MG. Operationalization of the SAMHSA model of recovery: a quality of life perspective. Qual Life Res. 2010;19:1-13.

34. Fukui S, Shimizu Y, Rapp CA. A cross-cultural study of recovery for people with psychiatric disabilities between U.S. and Japan. Community Ment Health J. 2012;48:804-12

35. Cavelti M, Wirtz M, Corrigan P, Vauth R. Recovery assessment scale: examining factor structure of the German version (RAS-G) in people with schizophrenia spectrum disorders. Eur Psychiatry. 2017:41:60-7.

36. Hoe S. Issues and procedures in adopting structural equation modeling techniques. JAQM. 2008:3:76-83.

\section{Submit your next manuscript to BioMed Central} and we will help you at every step:

- We accept pre-submission inquiries

- Our selector tool helps you to find the most relevant journal

- We provide round the clock customer support

- Convenient online submission

- Thorough peer review

- Inclusion in PubMed and all major indexing services

- Maximum visibility for your research

Submit your manuscript at www.biomedcentral.com/submit 